\title{
Spatial distribution of seismicity parameters in the Persian Plateau
}

\author{
Mohammad Ashtari Jafari \\ Institute of Geophysics, University of Tehran, P.O. BOX 16765-533, Tehran 16, Iran
}

(Received June 15, 2012; Revised February 26, 2013; Accepted February 26, 2013; Online published September 17, 2013)

\begin{abstract}
In this paper, seismicity parameters in the Persian Plateau are estimated and represented as colored maps. We depict the $b$-value variations as an indication of either changing material properties, or the heterogeneity of the stress field in this region. The lower $b$-values in some regions indicate that the seismic energy release in these areas is mostly provided by large magnitude earthquakes. Yet the $b$-value around northern CentralIran and Eastern Alborz seems to be near unity, which implies that the seismic energy release is compatible for larger and smaller earthquakes. We also compared our results with some existing seismological information on Iran. Regarding attenuation: low- $Q$ (high attenuation) regions approximately correspond to relatively lower $b$ value regions, and areas with nearly medium/high $b$-values correspond to high-velocity anomaly zones inferred from tomographic inversions. Meanwhile, regions associated with thrust and strike-slip faulting was associated with low/medium $b$-values. The higher $b$-values in NW Iran agree with the regional extensional tectonics and low/medium $b$-values were in agreement with regional compressional/strike-slip tectonics. In terms of geodynamics, this may be interpreted as an indication of a weak crust in NW Iran versus stronger crust (zones under stress) in other parts.
\end{abstract}

Key words: Spatial variations, $a$-value, $b$-value, regional tectonics, faulting-style.

\section{Introduction}

The Persian Plateau is under the influence of multiple convergences between the African, Indian and Eurasian plates, which has resulted in high mountain ranges along its northern (Alborz), northeastern (Kopeh-Dagh) and southwestern (Zagros) boundaries, and lower, rugged mountains along its eastern margins (East Iran). The seismicity pattern in the Persian Plateau represents a non-uniform distribution concentrated along the active fold and thrust mountain belts surrounding relatively aseismic undeformed rigid and stable blocks (Berberian, 2005). Catastrophic earthquakes are among the features of this plateau seismicity (Fig. 1). Several urban and industrial complexes have been developed near mountain foothills that are usually located near active faults, so even medium-sized earthquakes along such faults have destroyed many cities during historical and recent times (Ambraseys and Melville, 1982; Berberian, 1995). Interactions between reverse and strike-slip faults have been revealed by several clusters of events (Berberian and Yeats, 1999). Coseismic rupture studies are mainly realized by teleseismic modeling that usually uses segmentation of rupture in time and space (e.g. studies on Rudbar, Golbaf and Zirkuh earthquakes).

The nature of a spatial-temporal distribution of earthquake occurrence is a complicated phenomenon with complex nonlinear dynamics, so seismicity parameters (" $a$ " and " $b$ " values) can help reveal some aspects of the complexities. Gutenberg and Richter have shown that seismicity pa-

Copyright (C) The Society of Geomagnetism and Earth, Planetary and Space Sciences (SGEPSS); The Seismological Society of Japan; The Volcanological Society of Japan; The Geodetic Society of Japan; The Japanese Society for Planetary Sciences; TERRAPUB.

doi:10.5047/eps.2013.02.006 rameters may follow a power law. The $a$-value depends on the size distribution, and the time and volume window considered, and is a measure of seismic activity. The $b$-value is a tectonic parameter which indicates a measure of the relative abundance of greater to smaller earthquakes, and the stress and material conditions in the focal depth (Mogi, 1962; Scholz, 1968). As the $b$-value plays a key rule in present seismic hazard study theories and procedures, the results will be very useful for seismic hazard analysis in Iran.

In this study, we have only considered events after 1996, so it may be helpful to take a look at the development and installation of seismic stations in Iran. Several seismic stations have been in operation in Iran from the early sixties to monitor seismicity for seismic hazard studies. Mashhad, Shiraz, Tabriz and Tehran stations were among the first seismic stations in the country. Later, the events recorded by the Iranian Long Period Array (ILPA) have also been used to study regional seismicity. The ILPA comprises seven stations equipped with broadband seismometers located southwest of Tehran (Akasheh et al., 1976). ILPA data was not appropriate for studying the precise seismicity all around Iran because it enclosed only a 30-km-diameter circular area, and other sparsely distributed stations suffered the same problem. After the 1990 catastrophic Rudbar earthquake, the Institute of Geophysics of the University of Tehran decided to provide a better station coverage over Iran. Since late 1995, several stations have been installed in different regions of the country based on digital technology and radio transmission. Each station is equipped with threecomponent short-period seismometers, digitizer and transmitter. Continuous data are sent by radio links to the cen- 


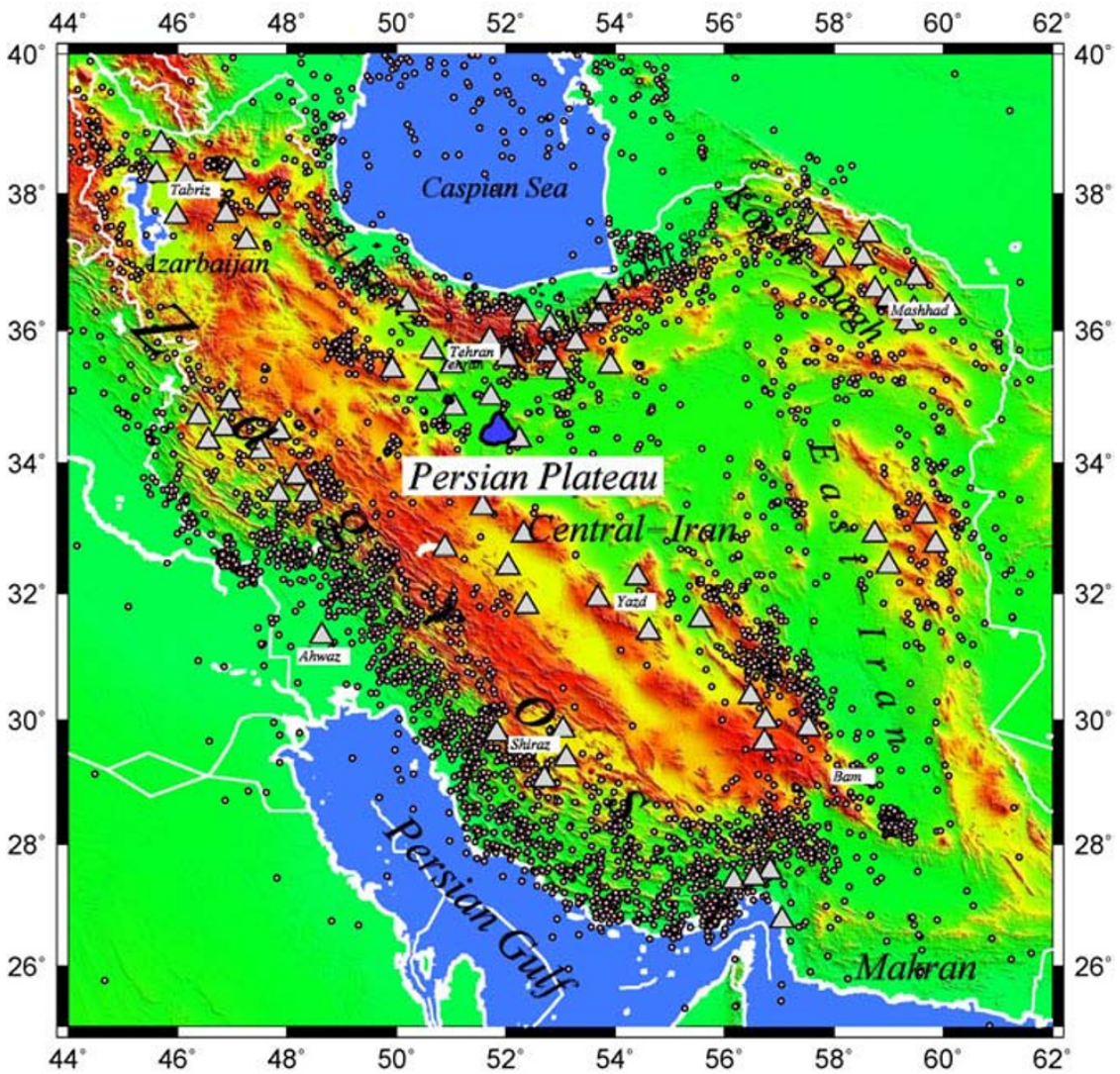

Fig. 1. Epicentral distribution of the earthquakes $\left(M_{\mathrm{n}} \geq 3.5\right.$; depth $\left.\geq 50 \mathrm{~km}\right)$ in the Persian Plateau from early 1996 to early 2013 and before declustering the events (events from IGUT). Gray triangles are IGUT seismic stations.

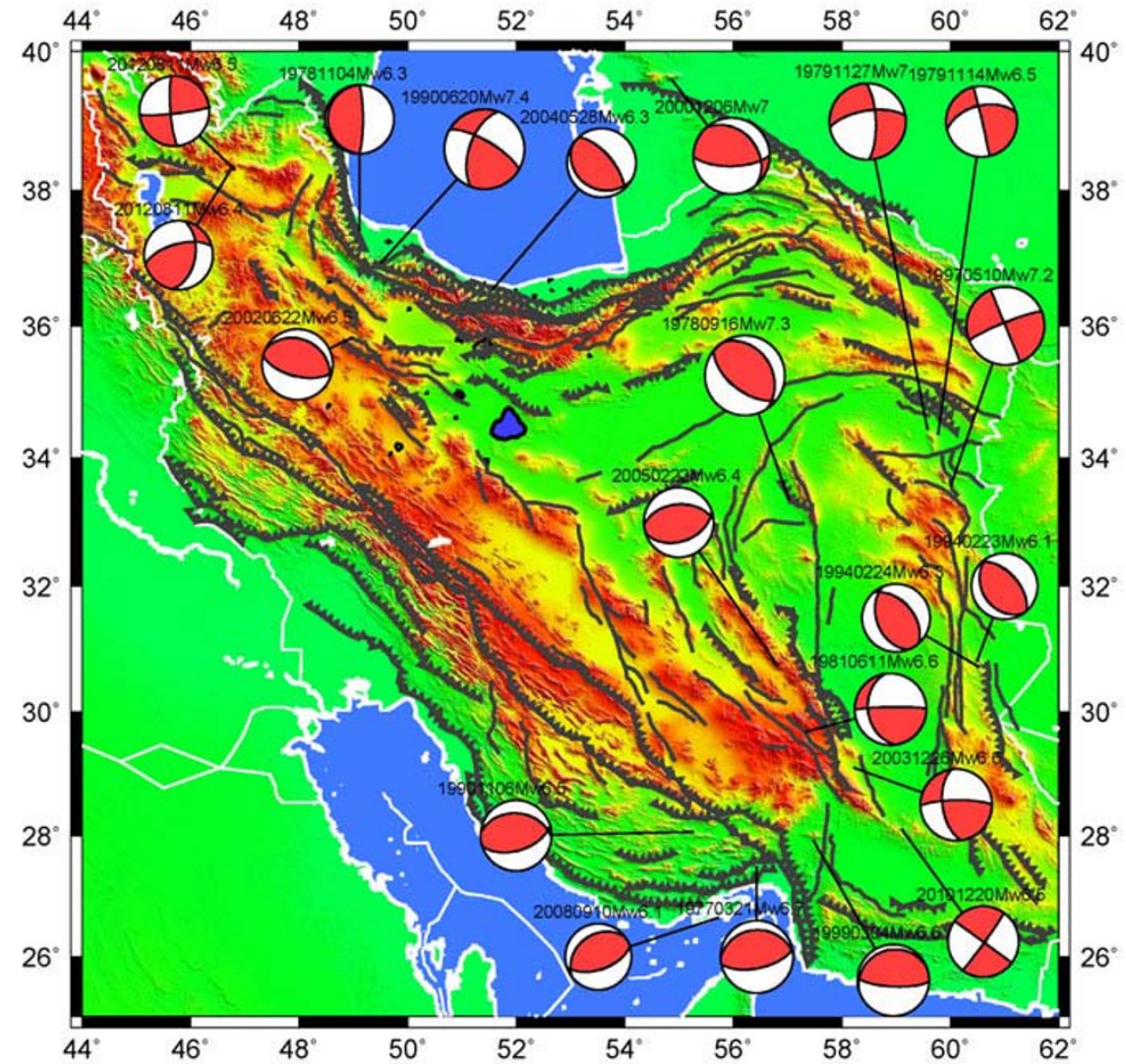

Fig. 2. Distribution of the CMT solutions in the Persian Plateau (events from GlobalCMT, $M_{\mathrm{w}}>6.0$ ). 
tral station, where they are time-stamped and a STA/LTA algorithm detects the events and stores them on permanent storage media. The recorded events of these stations can be extracted from the IGUT (Institute of Geophysics, University of Tehran) for further processings and constructing regional catalogues.

\section{Tectonic Settings}

The seismicity of the Persian Plateau has been studied by many different authors (Wilson, 1930; Niazi and Basford, 1968; Nowroozi, 1971, 1972, 1976; McKenzie, 1972; Kaila et al., 1974; Berberian, 1981, 1995; Shoja-Taheri and Niazi, 1981; Ambraseys and Melville, 1982; Ahmadi et al., 1989; Engdahl et al., 2006). This Plateau is located within the continental collision between the African and Eurasian plates, and includes recent volcanic activity, high mountain ranges and active faults. The collision between these two plates has uplifted mountain ranges like the Alborz and Zagros. This Plateau has undergone different mountain building phases that is characterized by concurrent magmatism and metamorphism, especially within the early Paleozoic, middle Triassic, early Jurassic and early Cretaceous (Berberian, 1981; Sengor et al., 1988).

The approximate rate of convergence between ArabiaEurasia has been estimated to be about $30 \mathrm{~mm} / \mathrm{yr}$ at longitude $50^{\circ} \mathrm{E}$ and $40 \mathrm{~mm} / \mathrm{yr}$ at longitude $60^{\circ} \mathrm{E}$ (Jackson, 1992; DeMets et al., 1994; Chu and Gordon, 1998). Vernant et al. (2004) suggested that the deformation is about $20 \mathrm{~mm} / \mathrm{yr}$ for the last Ma (Zagros: $10 \mathrm{~mm} / \mathrm{yr}$, Alborz: $8 \mathrm{~mm} / \mathrm{yr}$ and eastern-Iran: $16 \mathrm{~mm} / \mathrm{yr}$ ). Regional convergence is partitioned into a shortening perpendicular to the strike of the folds and faults, while active deformation is not uniformly distributed and consists of shortening, thickening, reverse and strike-slip faulting plus subduction of the oceanic crust. On the other hand, a large part of the shortening is taken up in mountain building (Alborz, Zagros and Kopeh-Dagh) and earthquakes, and some is accommodated in CentralIran. One can roughly divide the active faults of Iran into reverse and strike-slip faults. Active faults in Iran are mainly short-length compressive faults located within active foldthrust border zones plus strike-slip faults seen over narrow zones accompanied with reverse sub-faults. This is an example of the complex tectonic behavior of the reverse and strike-slip faults. The main features revealed by focal mechanism solutions are consistent with strike-slip and compressive motions (Fig. 2). Around Zagros, the reverse solutions are dominant, while in Alborz, Kopeh-Dagh and CentralIran, strike-slip solutions start to grow in number. The focal depth of earthquakes in Iran are mainly within 5-20 km (upper continental crust), although, in the regions associated with subduction (e.g. Makran), one would expect deeper earthquakes (Engdahl et al., 2006).

\section{Data and Method}

The frequency-magnitude relation (Gutenberg and Richter, 1944) is one of the well-documented empirical relations in earthquake seismology that represents the frequency of occurrence of earthquakes as a function of magnitude:

$$
\log _{10} N\left(M_{\mathrm{c}}\right)=a-b M,
$$

where $N$ is the cumulative number of earthquakes with a magnitude larger than the magnitude of completeness $\left(M_{\mathrm{c}}\right)$, and the $a$-value (seismic activity) and the $b$-value (size distribution) are constants to be determined (the magnitude scale that is used in this study is the Nuttli magnitude: $M_{\mathrm{n}}$; Nuttli, 1973). The $a$-value is a measure of seismic activity and depends on the largest seismic magnitude, the observation period length, and the size and stress level of the area. The $b$-value is the slope of the regression line, which is a constant, and which determines the rate of change in frequency of the earthquakes with increasing magnitude. Two well-known methods have been suggested for $b$-value estimations: the least squares and maximum likelihood methods. The least squares method (Pacheco and Sykes, 1992; Okal and Kirby, 1995; Scholz, 1997; Main, 2000; Lopez Pineda and Rebollar, 2005) is a method the application of which has no statistical foundation (Page, 1968; Bender, 1983). Sandri and Marzocchi (2007) numerically and analytically studied the biases introduced by the accumulation, logarithmic transformation and measurement errors resulting from this method. They showed that the method provides a great underestimation of the uncertainty and a significant bias (that also highly depend on the data size) in the estimation of the $b$-value, both for the binned and cumulative form of Eq. (1). Moreover, the effect of the measurement errors seems to be less significant than the bias introduced by the logarithmic transformation. Yet, the maximum likelihood method (Aki, 1965) has been extensively used for the estimation of the $b$-value (Eq. (2)). Marzocchi and Sandri (2003) found that Aki's formula, which assumes the magnitude to be a continuous random variable, leads to a significant bias in the estimation of the $b$-value, and a significant underestimation of its uncertainty. They show, however, that the corrected formula (the binned magnitudes; as employed in this paper by zmap) will strongly reduce the biases of the $b$-value and its uncertainty; however, the influence of the measurement errors appears negligible compared to the effects of the binned magnitudes:

$$
b=\frac{1}{M_{\text {mean }}-M_{\text {min }}} \log e,
$$

where $M_{\text {mean }}$ denotes the mean magnitude, and $M_{\text {min }}$ the minimum magnitude, of the employed catalogue. The uncertainty limit of this estimation is given by Eq. (3) as proposed by Shi and Bolt (1982):

$$
\sigma(b)=2.30 b^{2} \sqrt{\sum_{i=1}^{n}\left(M_{i}-M_{\text {mean }}\right) / n(n-1)},
$$

where $n$ is the total number of the events of the catalogue.

Considering the sparse distribution of local seismic stations (as mentioned in the Introduction) and the different errors associated with global earthquake catalogues (e.g. different magnitude scales, magnitude conversions, locations, etc...) it was decided to consider the Wiemer and Wyss (2002) suggestion to select a starting time for the seismicity parameter estimation. The suitable starting time to maximize the number of events is selected to be $t_{\mathrm{s}}=1996$. The hypocentral depths of the events have been limited to 

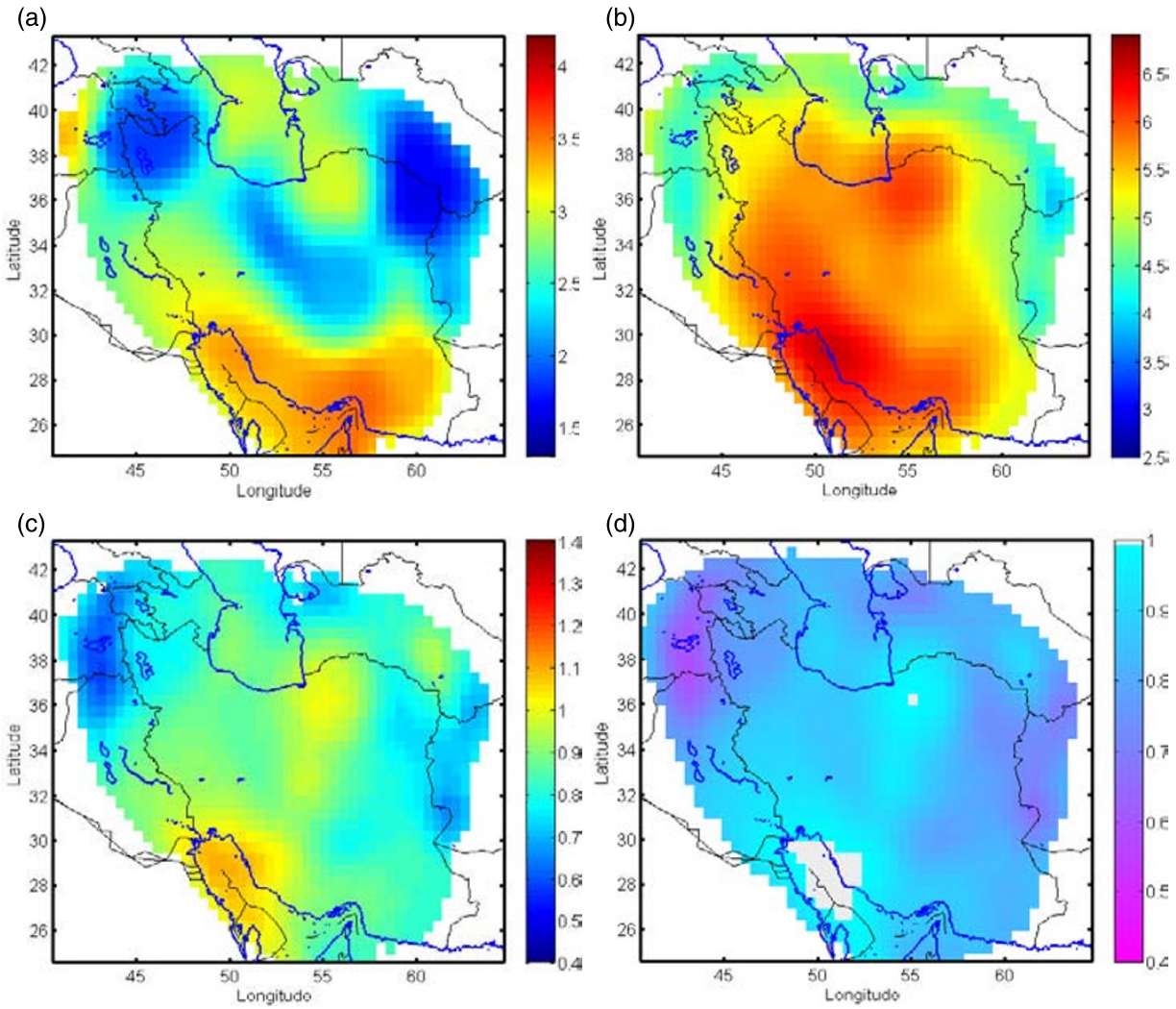

Fig. 3. Seismicity parameters map in the Persian Plateau before declustering the events: (a) magnitude of completeness ( $M_{\mathrm{c}}$ ); (b) $a$-value; (c) $b$-value; (d) significant $b$-values.
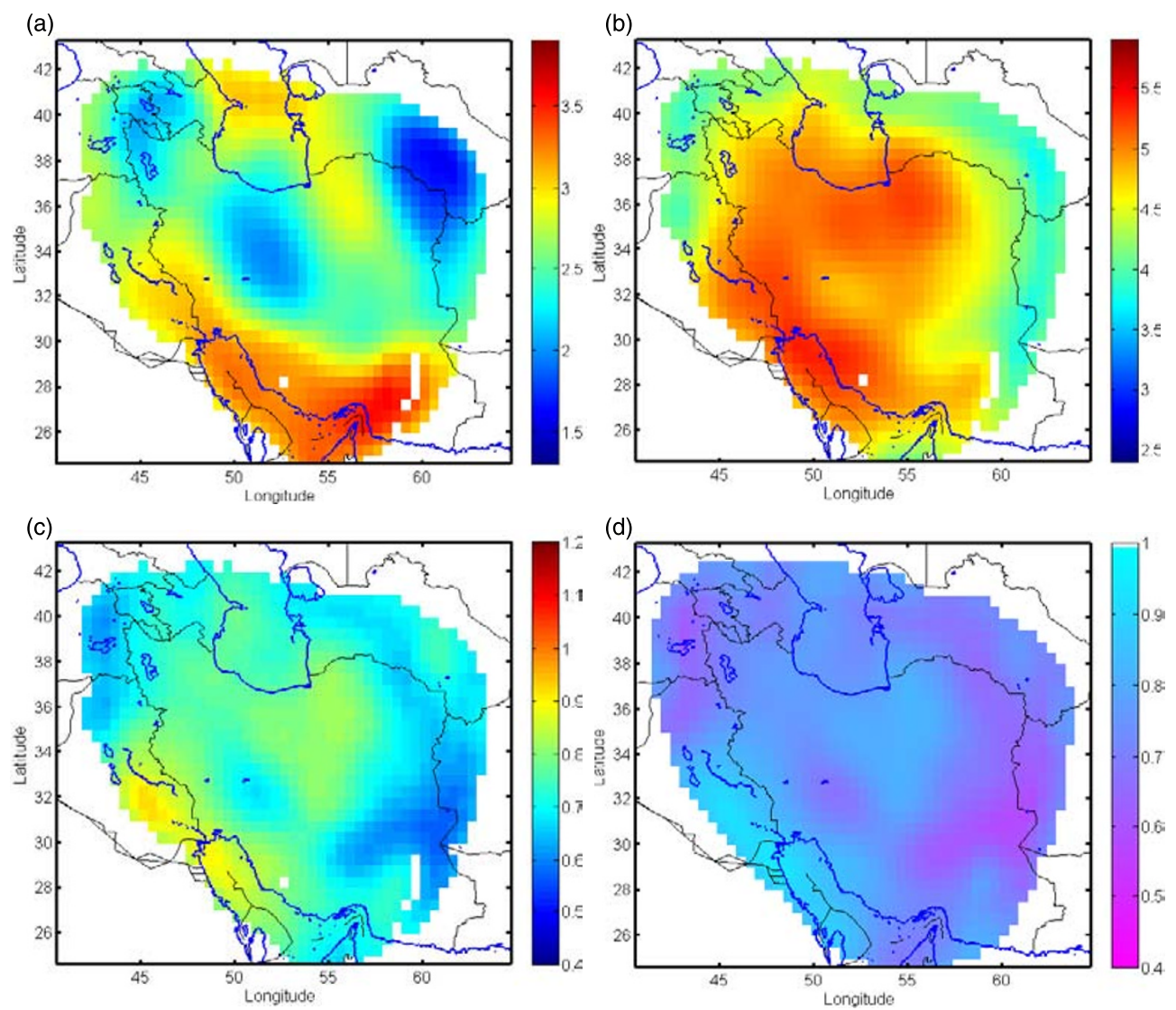

Fig. 4. Seismicity parameters map in the Persian Plateau after declustering the events: (a) magnitude of completeness $\left(M_{\mathrm{c}}\right)$; (b) $a$-value; (c) $b$-value; (d) significant $b$-values. 
crustal earthquakes (depth $\geq 50 \mathrm{~km}$ ) and all events have been binned in $\Delta M_{\mathrm{n}}=0.1$. The original data that were extracted from the IGUT catalogue (from early 1996 to early 2013) have been declustered by the method proposed by Reasenberg (1985). From 81152 events in the raw cata$\log , 24234$ events were identified as mainshocks and the remaining $70.14 \%$ of events were considered to be clustered events. Considering that the Persian Plateau shows a nonuniform seismic activity, in order to study the spatial variations of the seismicity parameters, the whole area was divided into $0.5 \times 0.5$ degree grids. All parameters $(a$ and $b$ values and $M_{\mathrm{c}}$ ) were calculated at the center of each grid point by considering the nearest 100 events, and only those earthquakes of magnitude greater than the magnitude of completeness $\left(M_{\mathrm{c}}\right)$ for each grid point. The $b$-value, the significant $b$-values, the $a$-value, and the magnitude of completeness, were mapped for the events before, and after, declustering and presented as colored maps (Figs. 3 and 4).

\section{Results}

As evident from Figs. 3 and 4, the seismicity parameter maps before, and after, declustering provide comparable results. The magnitude of completeness maps show that it is around $M_{\mathrm{n}}=2.5$ for inner parts of the Plateau and about $M_{\mathrm{n}}=3.0$ for outer parts (Figs. 3(a) and 4(a)). The $a$-value maps (Figs. 3(b) and 4(b)) indicate that values generally larger than 4.5 that may be taken as high seismicity rates in the Persian Plateau and surrounding area. The $b$ value estimations are about 0.8 to 0.9 for inner regions, and lower than 0.8 for outer regions, of this Plateau (Figs. 3(c) and 4(c)). Based on Figs. 3(d) and 4(d) that represent significant $b$-value maps according to Wiemer and Schorlemmer (2007) the $b$-values are generally lower than unity and there is no significant difference between $b$-values. The lower $b$ values in some regions indicate that the seismic energy release in these areas is mostly provided by large magnitude earthquakes. Yet the $b$-value around northern Central-Iran and Eastern Alborz seems to be near unity which implies that the seismic energy release is compatible for larger and smaller earthquakes.

\section{Discussions}

Several studies have revealed spatial variations in the frequency-magnitude distribution of different tectonic regimes (Wyss et al., 1997; Wiemer and Wyss, 1997). Some studies have indicated spatial and the temporal changes in the $b$-value before large earthquakes (Murase, 2004; Nakaya, 2006). Material heterogeneity and thermal gradients (Mogi, 1962; Warren and Latham, 1970) may also cause changes in $b$-values. Wyss et al. (2001) showed that a low-velocity zone started around a volume with a high $b$ value in the subducting slab at 140 to $150 \mathrm{~km}$ in depth and suggested that this may be an indication of magma generation at high $b$-value anomalies. The $b$-value of the deep earthquake zones of Alaska and New Zealand is high at a $95 \mathrm{~km}$ depth (Wiemer and Benoit, 1996). This observation was interpreted as being due to high pore pressure in this depth range, due to dehydration in the subducting slab. Therefore, high $b$-value anomalies may be found in a descending slab. The low-velocity zone in a mantle wedge was thought to be a path of magma ascent in northeastern Japan (Nakajima et al., 2001). Several studies have shown that the $b$-value is different for small and large earthquakes (Hamilton and McCloskey, 1997; Ikeya and Huang, 1997). High and low shear stresses may cause earthquakes having low and high $b$-values (Wyss, 1973; Schorlemmer et al., 2005). Along the creeping zone of the San-Andreas fault, earthquakes have high $b$-values which may indicate a low stress (high pore pressure). Other observations propose that the spatial variation in the $b$-value of aftershocks is related to the rupture process of the main shock (Bayrak and Ozturk, 2004). Almost all seismic hazard studies which are reflected in seismic hazard maps rely on $b$-value calculations, so temporal and spatial variations in the $b$-value will affect existing seismic hazard maps (Schorlemmer et al., 2005).

Different regions in the Persian Plateau experience a significant variation of heterogeneity laterally and vertically, but it seems that vertical tectonics, caused by the convergence between Arabia and Eurasia, is controlling the seismicity of Iran. Tectonic adjustment between different structural features (mountains, hills, valleys, etc...) has been increasing the seismic activity in various regions of the same Plateau. Although the seismicity of the Persian Plateau has not been deeply studied (to provide clear seismogenesis results) so as to provide sufficient information for clarifying the mechanisms for $b$-value variations, we can state that the different stress regimes are among the main reasons for the changes in seismicity parameters within different regions of this Plateau.

\section{Conclusions}

The uneven distribution of the $a$-value may clearly be an indication of the wide fluctuations of stress level and heterogeneity in the crust of the Persian Plateau. Large $a$-value regions (i.e. Alborz, Central-Iran, Kopeh-Dagh and Zagros) may be considered for greater rock fracture densities caused by strong structural movements and/or a low rheological strength of the crust causing brittle failure at lower stress levels. Higher $a$-values may also be related to the mutual tectonic adjustment between Zagros with the African Plate, and/or Alborz-Kopeh-Dagh with the Eurasian Plate. Lower $a$-values are also related to lower heterogeneities/fracturing of the crust caused by the tectonic processes of eastern Iran against the Indian Plate, and/or Azarbaijan against the Caucasian Plate.

Based on the range of the computed measures, the Plateau can be divided into low $(b \leq 1.0)$ and high $(b>$ $1.0)$ zones. Higher $b$-values can possibly be accounted for by low strength rocks that experience brittle failure at lower stress levels. They can also represent a relatively low stress in the seismogenic zones caused by episodic changes in the state of the tectonic coupling in each region. Lower $b$-values usually indicate areas including strike-slip and reverse faulting (Narteau et al., 2009) which is compatible with the typical features of the tectonics of Iran. An important result based on the $b$-value estimations (Figs. 3(c), 3(d), 4(c) and 4(d)) is that these values in Alborz, Azarbaijan, East and Central-Iran, Kopeh-Dagh and Zagros are around low values $(b \leq 1.0)$. Evidently these regions are those associated with thrust and strike slip faulting that tends to 
be under higher stress regimes (Schorlemmer et al., 2005). The world-wide subduction zones show $b$-values having a low value in a range from 0.53 to 0.74 (Bayrak et al., 2002) and this has been found to be the same in Makran. Masson et al. (2006) provide an explanation for the extensional tectonics in NW Iran based on a dense GPS network installed there. We interpret the $b$-values (Figs. 3(c) and 4(c)) in Azarbaijan and the surrounding area to be due to this extensional deformation. Meanwhile, the low/medium $b$-values in other parts of the Persian Plateau are under the influence of the convergence of tectonic forces from the African, Indian, and Eurasian Plates, presented regionally by thrust and strike-slip deformations. In terms of geodynamics, therefore, this configuration depicts a weak crust in NW Iran while other parts show a relatively stronger crust which is under higher compressional/sliding forces. Accordingly, it can be concluded that these values are closely related to the existing high deformation in the Persian Plateau.

Some of the existing seismological information enable us to compare our results with them. Comparing our $b$ value map (Figs. 3(c) and 4(c)) with the $L_{\mathrm{g}} Q$ attenuation map of Pasyanos et al. (2009) reveals that low- $Q$ (high attenuation) regions approximately correspond to relatively lower $b$-values, and vise versa. Koulakov (2011), and Alinaghi et al. (2007), demonstrated body and shear wave anomalies beneath Iran along different cross-sections resulted from tomographic inversions. The high-velocity anomalies of their cross-sections and maps are almost in agreement with medium/high $b$-value areas of this study (Figs. 3(c) and 4(c)).

Acknowledgments. I would like to thank Tomomi Okada and anonymous reviewers for their constructive comments and valuable suggestions. We acknowledge IGUT/IRSC (irsc.ut.ac.ir) for providing the IGUT catalogue. Some figures have been drawn by GMT (Wessel and Smith, 1991) and zmap (Wiemer, 2001) has been used for data processing and seismicity parameter estimations.

\section{References}

Ahmadi, G., N. Mostaghel, and A. A. Nowroozi, Earthquake risk analysis of Iran: Probabilistic seismic risk for various peak ground accelerations, Iranian J. Sci. Technol., B, 115-156, 1989.

Akasheh, B., I. Eshghi, and R. Soltanian, The Iranian Long Period Array (ILPA), J. Geophys., 42, 159-162, 1976.

Aki, K., Maximum likelihood estimate of $b$ in the formula $\log (N)=$ $a-b M$ and its confidence limits, Bull. Earthq. Res. Inst. Tokyo Univ., 43, 237-239, 1965.

Alinaghi, A., I. Koulakov, and I. Thybo, Seismic tomographic imaging of $\mathrm{P}$ - and S-waves velocity perturbations in the upper mantle beneath Iran, Geophys. J. Int., 169, 1089-1102, 2007.

Ambraseys, N. N. and C. P. Melville, A History of Persian Earthquakes, Cambridge University Press, UK, 1982.

Bayrak, Y. and S. Ozturk, Spatial and temporal variation of the aftershock sequence of the 1999 Izmit and Duzce earthquakes, Earth Planets Space, 56, 933-944, 2004.

Bayrak, Y., A. Yilmazturk, and S. Ozturk, Lateral variations of the modal (a/b) values for the different regions of the world, J. Geodyn., 34, 653666, 2002.

Bender, B., Maximum likelihood estimation of $b$ values for magnitude grouped data, Bull. Seismol. Soc. Am., 73, 831-851, 1983.

Berberian, M., Active faulting and tectonics of Iran, in Zagros-Hindu Kush-Himalaya Geodynamic Evolution, AGU Geodynamics Series, 33 69, 1981.

Berberian, M., Natural hazards and the first earthquake catalogue of Iran, IIEES-UNESCO, Iran, 1995.

Berberian, M., The 2003 Bam urban earthquake: A predictable seismotec- tonic pattern along the western margin of the rigid Lut block, southeast Iran, Earthq. Spectra, 21(S3), s35-s99, 2005.

Berberian, M. and R. S. Yeats, Patterns of historical earthquake rupture in the Iranian Plateau, Bull. Seismol. Soc. Am., 89, 120-139, 1999.

Chu, D. and R. G. Gordon, Current Plate motions across the Red Sea, Geophys. J. Int., 135, 313-328, 1998.

DeMets, C., R. G. Gordon, D. F. Argus, and S. Stein, Effect of recent revisions to the geomagnetic reversal time scale on estimates of current plate motions, Geophys. Res. Lett., 21, 2191-2194, 1994.

Engdahl, E. R., J. A. Jackson, S. C. Myers, E. A. Bergman, and K. Priestle, Relocation and assessment of seismicity in the Iran region, Geophys. J. Int., 167, 761-778, 2006.

GlobalCMT: www.globalcmt.org.

Gutenberg, B. and C. Richter, Frequency of earthquakes in California, Bull. Seismol. Soc. Am., 34, 185-188, 1944.

Hamilton, T. and J. McCloskey, Breakdown in power-law scaling in an analogue model of earthquake rupture and stick-slip, Geophys. Res. Lett., 24, 465-468, 1997.

Ikeya, M. and Q. Huang, Earthquake frequency and moment magnitude relations for mainshocks, foreshocks and aftershocks: Theoretical $b$ values, Episodes, 20, 181-184, 1997.

Jackson, J., Partitioning of strike slip and convergent motion between Eurasia and Arabia in Eastern Turkey and the Caucasus, J. Geophys. Res., 97(B9), 12471-12479, 1992.

Kaila, K. L., N. M. Rao, and H. Narain, Seismotectonic maps of southwest Asia region comprising eastern Turkey, Caucasus, Persian Plateau, Afghanistan and Hindukush, Bull. Seismol. Soc. Am., 64, 657-669, 1974.

Koulakov, I., High-frequency $\mathrm{P}$ and $\mathrm{S}$ velocity anomalies in the upper mantle beneath Asia from inversion of worldwide traveltime data, $J$. Geophys. Res., 116, B04301, 2011.

Lopez Pineda, L. and C. J. Rebollar, Source characteristics of the Mw 6.2 Loreto earthquake of 12 March 2003 that occurred in a transform fault in the middle of the Gulf of California, Mexico, Bull. Seismol. Soc. Am., 95, 419-430, 2005.

Main, I., Apparent breaks in scaling in the earthquake cumulative frequency-magnitude distribution: fact or artifact?, Bull. Seismol. Soc. Am., 90, 86-97, 2000.

Marzocchi, W. and L. Sandri, A review and new insights on the estimation of the $b$-value and its uncertainty, Ann. Geophys., 46, 1271-1282, 2003.

Masson, F., Y. Djamour, S. Van Gorp, J. Chery, M. Tatar, F. Tavakoli, H. Nankali, and P. Vernant, Extension in NW Iran driven by the motion of the South Caspian Basin, Earth Planet. Sci. Lett., 252, 180-188, 2006.

McKenzie, D., Active tectonics of the Mediterranean region, Geophys. J. R. Astron. Soc., 30, 109-185, 1972.

Mogi, K., Magnitude-frequency relation for elastic shocks accompanying fractures of various materials and some related problems in earthquakes, Bull. Earthq. Res. Inst. Univ. Tokyo, 40, 831-853, 1962.

Murase, K., A characteristic change in fractal dimension prior to the 2003 Tokachi-oki earthquake $\left(M_{J}=8.0\right)$ Hokkaido, northern Japan, Earth Planets Space, 56, 401-405, 2004.

Nakajima, J., T. Matsuzawa, A. Hasegawa, and D. Zhao, Three dimensional structures of $\mathrm{Vp}, \mathrm{Vs}$, and $\mathrm{Vp} / \mathrm{Vs}$ beneath the northeastern Japan arc: implications for arc magmatism and fluids, J. Geophys. Res., 106, 21843-21857, 2001.

Nakaya, S., Spatiotemporal variation in b value within the subducting slab prior to the 2003 Tokachi-oki earthquake (M 8.0) Japan, J. Geophys. Res., 111, B03311, 2006.

Narteau, C., S. Byrdina, P. Shebalin, and D. Schorlemmer, Common dependence on stress for the two fundamental laws of statistical seismology, Nature, 462, 642-645, 2009.

Niazi, M. and J. R. Basford, Seismicity of Iranian Plateau and Hindukush region, Bull. Seismol. Soc. Am., 58, 417-426, 1968.

Nowroozi, A. A., Seismotectonics of the Persian Plateau, eastern Turkey, Caucasus, and Hindukush Regions, Bull. Seismol. Soc. Am., 61, $317-$ 341, 1971.

Nowroozi, A. A., Focal mechanisms of earthquakes in Persia, Turkey, west Pakistan, and Afghanistan and plate tectonics of the Middle East, Bull. Seismol. Soc. Am., 62, 823-850, 1972.

Nowroozi, A. A., Seismotectonic provinces of Iran, Bull. Seismol. Soc. Am., 66, 1249-1276, 1976.

Nuttli, O. W., Seismic wave attenuation and magnitude relations for eastern North America, J. Geophys. Res., 78, 876-885, 1973.

Okal, E. A. and S. H. Kirby, Frequency-moment distribution of deep earthquake; implications for the seismogenic zone at the bottom of slabs, Phys. Earth Planet. Inter. 92, 169-187, 1995. 
Pacheco, J. F. and L. R. Sykes, Seismic moment catalog of large shallow earthquakes, 1900 to 1989, Bull. Seismol. Soc. Am., 82, 1306-1349, 1992.

Page, R., Aftershocks and microaftershocks of the Great Alaska earthquake of 1964, Bull. Seismol. Soc. Am., 58, 1131-1168, 1968.

Pasyanos, M. E., E. M. Matzel, W. R. Walter, and A. J. Rodgers, Broadband Lg Attenuation Modeling of the Middle East, Geophys. J. Int., 177, 1166-1176, 2009.

Reasenberg, P. A., Second order moment of central California seismicity 1969-82, J. Geophys. Res., 90, 5479-5495, 1985.

Sandri, L. and W. Marzocchi, A technical note on the bias in the estimation of the $b$-value and its uncertainty through the Least Squares technique, Annal. Geophys., 50, 329-339, 2007.

Scholz, C. H., The frequency-magnitude relation of microfracturing in rock and its relation to earthquakes, Bull. Seismol. Soc. Am., 58, 399415,1968

Scholz, C. H., Size distributions for large and small earthquakes, Bull. Seismol. Soc. Am., 87, 1074-1077, 1997.

Schorlemmer, D., S. Wiemer, and M. Wyss, Variations in earthquake-size distribution across different stress regimes, Nature, 437, 539-542, 2005.

Sengor, A. M. C., D. Altiner, A. Cin, T. Ustaomer, and K. J. Hsu, Origin and assembly of the Tethyside orogenic collage at the expense of Gondwana Land, in Gondwana and Tethys, Oxford University Press, 37, 119-181, 1988.

Shi, Y. and B. A. Bolt, The standard error of the magnitude-frequency $b$ value, Bull. Seismol. Soc. Am., 72, 1677-1687, 1982.

Shoja-Taheri, J. and M. Niazi, Seismicity of the Iranian Plateau and bordering regions, Bull. Seismol. Soc. Am., 71, 477-489, 1981.

Vernant, P., F. Nilforushan, D. Hatzfeld, M. Abassi, C. Vigney, F. Mason, H. Nankali, J. Martinod, M. Ashtiany, R. Bayer, F. Tavakoli, and J. Chery, Present day crustal deformation and plate kinematics in Middle East constrained by GPS measurements in Iran and north Oman,
Geophys. J. Int., 157, 381-398, 2004.

Warren, N. W. and G. V. Latham, An experimental study of thermally induced microfracturing and its relation to volcanic seismicity, J. Geophys. Res., 75, 4455-4464, 1970.

Wessel, P. and W. H. F. Smith, Free software helps map and display data, Eos, 72, 441-446, 1991.

Wiemer, S., A software package to analyze seismicity: zmap, Seismol. Res. Lett., 72, 374-383, 2001.

Wiemer, S. and J. P. Benoit, Mapping the $b$-value anomaly at $100 \mathrm{~km}$ depth in the Alaska and New Zealand subduction zones, Geophys. Res. Lett., 23, 1557-1560, 1996.

Wiemer, S. and D. Schorlemmer, ALM: An Asperity-based Likelihood Model for California, Seismol. Res. Lett., 78, 134-140, 2007.

Wiemer, S. and M. Wyss, Mapping the frequency-magnitude distribution in asperities: An improved technique to calculate recurrence times, $J$. Geophys. Res., 102, 15115-15128, 1997.

Wiemer, S. and M. Wyss, Mapping spatial variability of the frequencymagnitude distribution of earthquakes, Adv. Geophys., 2002.

Wilson, A. T., Earthquake in Persia, Bull. School Orient. Stud., 6, 103-131, 1930.

Wyss, M., Towards a physical understanding of the earthquake frequency distribution, Geophys. J. R. Astron. Soc., 31, 341-359, 1973.

Wyss, M., K. Shimazaki, and S. Wiemer, Mapping active magma chambers by b values beneath the off-Ito volcano, Japan, J. Geophys. Res., 102(B9), 20413-20433, 1997.

Wyss, M., A. Hasegawa, and J. Nakajima, Source and path of magma for volcanoes in the subduction zone of northeastern Japan, Geophys. Res. Lett., 28, 1819-1822, 2001.

M. Ashtari Jafari (e-mail: muhammad@ut.ac.ir) 